\title{
Educação superior no Brasil e a utilização da Educação a Distância como estratégia de expansão e massificação
}

\author{
Higher education in Brazil and the use of Distance Education as a strategy for \\ expansion and massification \\ Educación superior en Brasil y la utilización de la Educación a Distancia como \\ estrategia de expansión y masificación \\ ALDA MARIA DUARTE ARAÚJO CASTRO \\ NATANIEL DA VERA-CRUZ GONÇALVES ARAÚJO
}

\begin{abstract}
Resumo: Analisa a expansão da educação superior a distância e a relação com a massificação do ensino. Pressupõe que essa expansão é motivada pela importância que o conhecimento e a competitividade ocupam na sociedade global. Utiliza uma abordagem crítica que busca explicar o problema considerando as suas mediações. A modalidade a distância tem contribuído para a expansão e massificação da educação superior com ênfase no setor privado, desobrigando, cada vez mais, o Estado de assumir a educação como bem público.
\end{abstract}

Palavras-chave: Educação Superior; Educação a Distância; Expansão; Massificação.

Abstract: It analyzes the expansion of the distance higher education and its contributions to the teaching massification. It is assumed that this expansion is motivated by the importance that the knowledge and competitiveness occupy in society nowadays. It uses a critical approach that aims to explain the problem considering its mediations. The distance education has contributed to the expansion and massification of higher education, mainly in the private segment, increasingly discharging the state of assuming the education as a public welfare.

Keywords: higher education; distance education; expansion; massification.

Resumen: Analiza la expansión de la educación superior a distancia y la relación con la masificación de la enseñanza. Parte del presupuesto de que esa expansión es motivada por la importancia que el conocimiento y la competitividad ocupan en la sociedad global. Utiliza un abordaje crítico que busca explicar el problema considerando sus mediaciones. La modalidad a distancia ha contribuido para la expansión y masificación de la educación superior con énfasis en el sector privado, desobligando, cada vez más, al Estado de asumir la educación como bien público.

Palabras clave: Educación Superior; Educación a Distancia; Expansión; Masificación. 


\section{INTRODUÇÃO}

O artigo analisa a expansão da Educação superior a distância e sua relação com a massificação do sistema educacional. Parte-se da premissa de que essa expansão é motivada, entre outros fatores, pela importância que o conhecimento e a competitividade adquiriram no mundo globalizado em razão de suas estreitas relações com o mundo do trabalho, e com o estabelecimento de novos padrões de competência econômica internacional. Os países desenvolvidos e em desenvolvimento tiveram que se adaptar às novas tendências globais. Isso afetou a forma como eles operacionalizavam seus sistemas educacionais, considerando que a acumulação do conhecimento e sua aplicação se converteram em fatores preponderantes do desenvolvimento econômico, passando a determinar, cada vez mais, a vantagem competitiva de um país na economia mundial (CASTEL, 1999). Nesse cenário, os países sentiram a necessidade de reformar seus respectivos sistemas de ensino, utilizando estratégias diferenciadas para aumentar a cobertura; entre elas, a educação a distância.

Para discutir o fenômeno da massificação da Educação superior no Brasil tem-se como referência os estudos de Trow $(1974,2005)$. O autor, ao analisar as tendências expansionistas da Educação superior, identificou a configuração de três tipos de sistemas educacionais, os quais denominou sistema de elite, sistema de massa e sistema universal, caracterizados pelo atendimento quantitativo e pela complexidade das funções institucionais.

$\mathrm{Na}$ primeira seção, discute-se a importância que o conhecimento e a competitividade ocupam na sociedade contemporânea, o que tem propiciado exigências no aumento de cobertura dos sistemas de educação superior em âmbito mundial. Na segunda seção, analisam-se as diretrizes dos organismos internacionais para a educação superior, evidenciando que elas apontam a modalidade da educação a distância como estratégia fundamental para o atendimento da demanda por esse nível de ensino. E na terceira seção, apresenta os dados da expansão da educação a distância no Brasil tendo, como referência, o número de vagas ofertadas, o número de inscritos e as matrículas das redes públicas e privadas.

Os dados sinalizam para um aumento significativo das matrículas, o que permitiu elevar as taxas líquidas e brutas de atendimento a esse nível de ensino. No entanto, verifica-se que essa grande expansão quantitativa ocorre, principalmente, no setor privado, desobrigando, cada vez mais, o estado de suas funções sociais e de sua opção de educação como bem público e de direito de todos. 


\section{CONHECIMENTO E COMPETITIVIDADE: NOVAS DEMANDAS GLOBAIS PARA A EDUCAÇÃO SUPERIOR}

Um dos principais traços do mundo atual é a centralidade ocupada pelo conhecimento e a sua permeabilidade em todas as áreas da vida humana. Esse fato é tão acentuado que Castells (1999) fala sobre o surgimento de uma nova economia cuja base é a informação/conhecimento. Para o autor, "a informação e o conhecimento sempre foram elementos cruciais no crescimento da economia, e a evolução da tecnologia determinou, em grande parte, a capacidade produtiva da sociedade e os padrões de vida, bem como formas sociais de organização econômica" (p. 87). Muitos fatos atestam essa verdade, entre eles, o processo de globalização, a multiplicidade de canais que fazem a informação circular no mundo em tempo real e a implementação das ideias neoliberais que redefiniram os tipos de concorrência do capitalismo mundial.

Essas mudanças realocaram valores e comportamentos além de instituírem o conhecimento e a informação como elementos centrais e catalisadores do que se chama de competitividade e passaram a ser integradas ao próprio capital, que começa a depender desses fatores para a acumulação e a reprodução. Nessa lógica, Bernheim e Chauí (2008) afirmam que "[...] o capital intelectual está se tornando o principal pecúlio das empresas. Estima-se que, hoje, mais da metade do PIB das maiores economias da OCDE estão baseadas no conhecimento"

(p. 7). Esse fato repercute diretamente na Educação superior na medida em que parte significativa dessa formação e desse conhecimento é ali produzida. Para Bernheim e Chauí (2008) a Educação superior, desde a sua origem, tem perseguido a meta de criar, transmitir e disseminar conhecimento. Portanto, se o conhecimento ocupa, hoje, lugar central nos processos que configuram a sociedade contemporânea, as instituições que trabalham com e sobre o conhecimento participam também dessa centralidade. Essa consideração levou a uma nova análise das relações entre a sociedade e as instituições de Educação superior, bem como a fortalecer a relevância de seu papel estratégico.

Nesse sentido, percebe-se a estreita relação entre conhecimento e desenvolvimento econômico no mundo atual. Isso configura um retorno à Teoria do Capital Humano, proposta por Theodore Schultz, a qual se constitui, em sua essência, em uma teoria econômica, tendo exercido profunda influência, a princípio, no período desenvolvimentista, ao asseverar que a educação se constitui em bem econômico a ser consumido e com desdobramentos nos futuros salários e no grau de desenvolvimento das nações. De acordo com Schultz (1961) 
“[...] qualquer capacidade produzida pelo investimento humano se torna uma parte do agente humano e, portanto, não pode ser vendida. Mesmo assim, está “ em contato com o mercado", afetando o aumento dos salários e vencimentos que o agente humano pode ganhar. Esse aumento resultante nos salários é o rendimento sobre o investimento." (p. 8 - tradução livre). ${ }^{1}$

Dessa forma, existiria uma relação unívoca entre conhecimento e nível de desenvolvimento das pessoas, das famílias e dos países. Segundo Cabrito (2002), a criação da Teoria do Capital Humano se desenvolveu em período de intensa escassez de trabalhadores qualificados no contexto após a Segunda Guerra Mundial. Um dos desdobramentos dessa escassez foi a pressão feita na perspectiva de expansão dos sistemas educacionais como forma de suprimento dessa grande demanda.

Em seu nascedouro, a Teoria do Capital Humano tentava demonstrar a relação existente entre o grau de escolaridade dos indivíduos e o grau de desenvolvimento alcançado pelos países, em razão de que o investimento nas habilidades humanas tem implicação no grau de competitividade e no desenvolvimento econômico de uma nação. Assim, podia valer mais investir em capital humano do que em outras formas de capital.

A teoria do Capital Humano encerra em si várias contradições; um dos argumentos contrários aponta para o cuidado que se deve ter com a culpabilidade alocada no indivíduo na condição de responsável pelo fracasso econômico. Uma outra crítica a essa visão economicista diz respeito à áurea que a educação passa a assumir de entidade redentora de uma sociedade, quando, na verdade, a educação faz parte das instituições que influenciam as mudanças de um país, mas, por si só, não muda nenhuma nação. Na visão de Oliveira (2000), uma das contradições reside no fato de que essa teoria, ao depositar grande ênfase no indivíduo e na educação, termina por camuflar a lógica e os reais interesses do capital, na medida em que é colocada na educação "[...] a expectativa de que esta possa, através da mobilidade social, melhorar os mecanismos de distribuição de renda e inserção produtiva, através do preparo dos indivíduos para o mercado de trabalho" (p. 91).

Os organismos internacionais incorporaram essa lógica a seus discursos e os documentos originários do Banco Mundial, como "Higher Education in Developing Countries: Peril and Promises" (Banco Mundial, 2000) passaram a defender o entendimento de que a relação entre a riqueza e a pobreza é diretamente proporcional à qualidade da educação superior. Segundo o documento, na atualidade, a riqueza mundial está cada vez menos concentrada em fábricas, terra,

$[\ldots]$ any capability produced by human investment becomes a part of the human agent and hence cannot be sold; it is nevertheless "in touch with the market place" by affecting the wages and salaries the human agent can earn. The resulting increase in earnings is the yield on the investment. 
ferramentas e maquinarias; os fatores decisivos para a economia mundial são: o conhecimento, as habilidades e a desenvoltura das pessoas. O capital humano de alta qualidade se desenvolve em sistemas educacionais muito bem qualificados, nos quais a educação superior ministra as habilidades avançadas mais requeridas atualmente no mundo do trabalho.

Outros documentos e conferências mundiais foram realizadas com o propósito de reafirmar a importância que o conhecimento tem em um mundo cada vez mais competitivo. A Unesco realizou em Paris duas Conferências Mundiais para discutir a educação superior (1998 e 2009); nessas duas conferências foi reafirmada a importância que a educação superior ocupa como alternativa para os vários desafios do mundo contemporâneo; além de ser de extrema importância para o desenvolvimento econômico dos países na medida em que os novos conhecimentos, inventos, descobertas e patentes criadas movem o capitalismo, consequentemente, o mundo.

Esse cenário tem levado os países a uma expansão de seus sistemas de ensino superior, seguindo as diretrizes do Banco Mundial (1996, 2000, 2002) que têm orientado a utilização de diferentes estratégias, entre elas, a diversificação institucional, a modalidade da educação a distância e a privatização do sistema. No entendimento dos organismos internacionais, essas estratégias têm permitido um acelerado crescimento da educação superior em todos os países do mundo, transformando os sistemas tradicionais em sistemas mais modernos, maiores, mais diversos e complexos.

Para Trow (2005), o rápido crescimento do ensino superior após a Segunda Guerra Mundial nas sociedades industriais avançadas esconde dois processos fundamentalmente diferentes; um deles foi a expansão das universidades de elite - o crescimento das funções universitárias tradicionais, embora modificadas; o outro foi a transformação de sistemas universitários de elite em sistemas de ensino superior de massa, com novas universidades e uma variedade expressiva de funções. $O$ autor admite três tipos de sistemas de educação superior: o sistema de elite, definido por atender até 15\% do grupo etário de 18 a 24 anos, cujo objetivo consiste em preparar a classe dominante e garantir a perpetuação de sua condição de comando, com o acesso quase restrito a alunos das classes sociais mais favorecidas; o sistema de massa, caracterizado por atender entre 16\% e 50\% do grupo etário entre 18 a 24 anos; esse sistema teria como objetivo a transmissão de competências com vistas à preparação para uma ampla gama de funções demandadas pelas elites técnicas e econômicas; e o terceiro seria o sistema universal, que ocorre quando as matrículas compreendem mais de 50\% 
da faixa etária de 18 a 24 anos; esse tipo de sistema possibilitaria o acesso de "toda a população" às rápidas mudanças sociais e tecnológicas, tendo como único requisito a terminalidade do ensino médio.

O crescimento do ensino superior é uma realidade global. Segundo dados apresentados no relatório "Trends in Global Higher Education" (UNESCO, 2009), a percentagem de taxa líquida ${ }^{2}$ de matrículas no ensino superior cresceu de $19 \%$ em 2000 para 26\% em 2007, com vantagens para os países desenvolvidos. Existia, à época do estudo. 2007, cerca de 150,6 milhões de alunos do ensino superior em todo o mundo, aproximadamente um aumento de $53 \%$ em relação a 2000. No entanto, essa expansão não ocorre da mesma forma em todos os paises. Nos Estados Unidos da América, assiste-se a um ensino superior em massa, com uma taxa real de educação superior rondando os 40\%, desde a década de 1960, consequentemente, sua evolução para um sistema universal Idem).

Ainda, segundo dados desse mesmo documento da Unesco, a tendência para a massificação aumentará nos próximos anos, embora os países não se situem no mesmo patamar de atendimento. É alarmante a diferença entre os países desenvolvidos e em desenvolvimento no atendimento à educação superior. Essa diferença pode ser encontrada entre países ricos e pobres e, no interior de cada país, entre as elites e as classes populares.

$\mathrm{Na}$ América Latina, a taxa real de educação superior é ainda metade daquela registrada nos países desenvolvidos; o Brasil, por exemplo, em 2001, tinha apenas $8,9 \%$ dos jovens com idades compreendidas entre os 18 a 24 anos regularmente matriculados no ensino superior chegando, em 2016, com um atendimento de $17,8 \%$. Isso na visão de Trow (2005) caracterizaria um sistema superior de massa. A Taxa Bruta de matrícula³, em 2001, era de 15,1\% e chegou a $32,6 \%$, o que indica que a distorção idade/série é um dos componentes estruturais da Educação Superior brasileira. Em ambos os casos, os dados indicam um crescimento bastante significativo, conforme pode ser visualizado no Gráfico 1.

2 Expressa o percentual de pessoas matriculadas em determinado nível de ensino na idade ou faixa etária teoricamente adequada a esse nível em relação à população na faixa etária teoricamente adequada ao mesmo nível de ensino. (MEC/INEP 2004, p. 13).

3 A taxa bruta expressa o percentual da matrícula total em determinado nível de ensino em relação à população na faixa etária teoricamente adequada para frequentar esse nível de ensino. (MEC/INEP, 2004, p. 13). 
Escolarização Bruta e Líquida 18 a 24 anos - Brasil 2001-2015

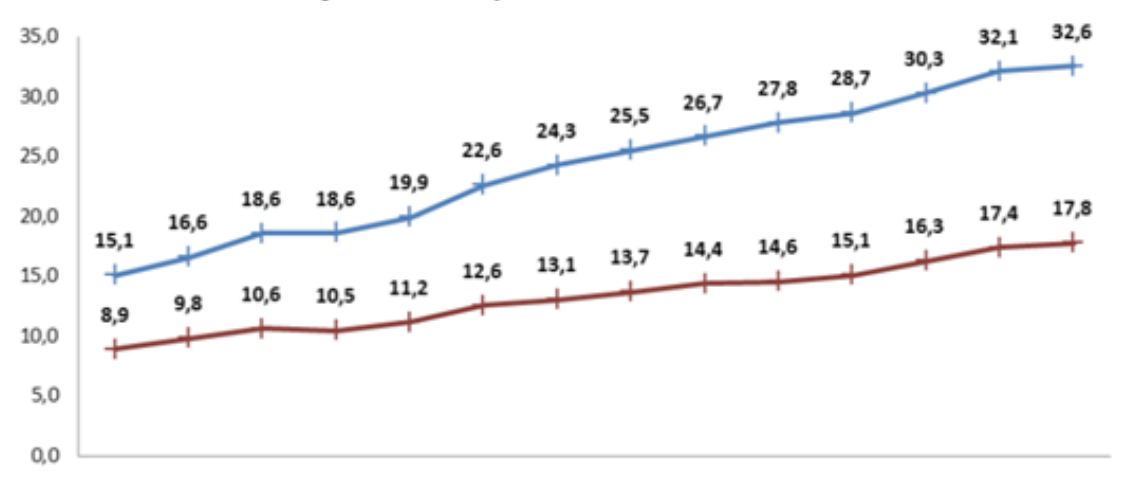

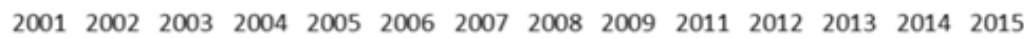

-Bruta -Liquida

Fonte: Brasil/Mec/Inep. Censo da Educação superior 2016 (p.4).

A expansão da Educação superior brasileira está associada às políticas implementadas no Brasil após a aprovação da Lei nº 9.394/96, de Diretrizes e Bases (BRASIL, 2006), que orientaram a flexibilização do atendimento, a diversificação institucional, a ampliação do número de matriculas por meio de políticas focais, a utilização da educação a distância e a privatização. Para Sguissardi (2015), na expansão da Educação Superior brasileira, estão sendo anuladas as fronteiras entre o público e o privado/mercantil; as políticas implementadas promoveram uma expansão, que se mantém como de elite e de alta qualificação para poucos, enquanto adquire traços de sistema de massas e de baixa qualificação para muitos.

Entre as políticas de expansão adotadas, merecem destaque as Políticas de Educação a Distância, modalidade que permite, entre outras questões, o atendimento a um maior contingente de alunos com custos reduzidos. As políticas de EAD têm contribuído, significativamente, para que o Brasil expanda as matrículas nesse nível de ensino. Os dados do Gráfico 1 mostram um crescente aumento da taxa líquida, de 8,9\% em 2001 para 17,8\% em 2015, o que, na perspectiva teórica desenvolvida por Trow (2005), caracterizaria o sistema de Educação Superior brasileiro como de massa.

A orientação do uso da modalidade de EAD, para a expansão do sistema de Educação Superior, pode ser encontrada nos documentos de políticas nacionais e supranacionais, elaboradas por organismos internacionais. 


\section{AS DIRETRIZES DOS ORGANISMOS INTERNACIONAIS: A ÊNFASE NA MODALIDADE A DISTÂNCIA COMO ESTRATÉGIA DE EXPANSÃO}

Nas últimas décadas, a modalidade de educação a distância tornou-se uma grande estratégia para atender às demandas por formação em qualquer nível educacional. Essa centralidade da EaD está relacionada, em grande parte, ao desenvolvimento acentuado das novas tecnologias da informação e comunicação (NTICs), as quais têm servido como interface na comunicação humana em diversas áreas do cotidiano. No campo educacional, a EaD tem despontado como alternativa para a expansão do ensino superior por suas potencialidades de atender a um grande contingente populacional e de reduzir os investimentos governamentais na área. Segundo Cabral Neto e Castro (2014), a EaD passa a integrar a atual agenda brasileira de reformas educacionais visando a aumentar a cobertura, a universalização e a equidade do acesso à Educação Superior.

A utilização, em larga escala da $\mathrm{EaD}$, é uma tendência recente, que encontra respaldo nas orientações dos organismos internacionais, entre eles, o Banco Mundial e a Unesco, que têm realizado eventos internacionais, produzido documentos orientadores que direcionam os países, principalmente em desenvolvimento, a expandir a cobertura dos seus sistemas de ensino superior utilizando, para isso, a educação a distância. Segundo Oliveira (2000), a minimização do poder estatal, principalmente, na década de 1990, enfraqueceu sua capacidade de elaborar políticas próprias, favorecendo a entrada em cena das agências multilaterais, as quais vêm implementando a reforma política neoliberal. A Unesco e o Banco Mundial vêm produzindo documentos e financiando projetos em diversas áreas educacionais.

Dessa forma, países como o Brasil, signatário das convenções realizadas pelos organismos internacionais, têm implementado políticas educacionais que incentivam a modalidade da EAD, aumentando a cobertura de matrículas no ensino superior, reduzindo o seu déficit educacional e contribuindo para fazer a transição do sistema de elite para um sistema de educação de massa.

Duas Conferências realizadas pela Unesco foram determinantes nas orientações para a expansão da educação superior na modalidade a distância. A primeira, ocorrida em Paris, denominada "Declaração Mundial sobre educação superior no século XXI: visão e ação” (UNESCO, 1998). Nessa Declaração, já se vislumbrava o potencial das tecnologias para a educação e o desafio que ela representava para os países em desenvolvimento. A referida Declaração afirmava que as rápidas inovações provocadas pelas tecnologias de informação e comunicação iriam alterar a forma como o conhecimento é desenvolvido, 
adquirido e transmitido. A Declaração de Paris (UNESCO,1998) evidenciava que os países que não acompanhassem essa tendência ficariam na contramão da história, visto que a globalização ultrapassa fronteiras. Portanto, os países que não estivessem preparados para esses novos desafios ficariam à margem dos métodos internacionais de ensino-aprendizagem sem fronteiras.

Posteriormente, a Conferência Mundial Sobre Ensino Superior 2009: "As Novas Dinâmicas do Ensino Superior e Pesquisas para a Mudança e o Desenvolvimento Social" (UNESCO, 2009) referenda as discussões da Conferência de 1998 no que se refere à diversificação e à utilização da educação a distância como forma de ampliar a igualdade de oportunidades e de ampliação do acesso. Ao tratar do acesso, equidade e qualidade, a ênfase da Declaração de 2009 recai na aprendizagem aberta e a distância, reforçando, assim, que o uso das tecnologias e da informação oferece as oportunidades para o acesso à educação superior.

A tônica da utilização da educação a distância como forma de superar o déficit das matrículas na educação superior também encontra respaldo nas diretrizes do Banco Mundial (BM) que, em seus documentos orientadores, prevê que o poder dos docentes e a centralidade da sala de aula declinarão, inexoravelmente, à medida que se for generalizando o uso de tecnologias pedagógicas on-line. $\mathrm{O}$ documento, lançado pelo Banco Mundial, intitulado "Prioridades y Estratégias para la Educación", faz ampla apologia a respeito da utilização da educação a distância como resposta ao grave problema brasileiro da expansão do ensino superior (BANCO MUNDIAL, 1996).

O cerne da apologia do BM sobre a defesa da modalidade a distância assenta-se, nos seus custos pretensamente baixos e não considera, a priori, o fundamento de uma formação consistente que contribua para a solução dos problemas encontrados na educação brasileira, relacionados à qualidade do ensino ofertado e suas consequências para o déficit de aprendizagem, acumulado ao longo dos anos em todos os níveis da educação.

O Documento do Banco Mundial, intitulado "Higher Education in Developing Countries" (2000) afirma que "A educação a distância se apresenta como grande potencial para o desenvolvimento do mundo, pois se constitui em poderoso canal para integrar à educação grupos até então excluídos" (BANCO MUNDIAL, 2000, p. 31). Em documento específico para o Brasil intitulado "Higher Education in Brazil: Challenges and Options" (2002) há uma recomendação específica a respeito da utilização da $\mathrm{EaD}$ no Brasil, ao afirmar que 
"Se a experiência de outros países serve de guia, a principal estratégia para responder a este aumento da demanda no Brasil pode e deve ser uma estratégia de diversificação que se baseia principalmente em criações de programas de ensino a distância e da expansão das matrículas em instituições que não enfatizam a pesquisa em sua missão. Mas o Brasil também deve considerar o papel das universidades federais no cumprimento de algumas dessas demandas"4 (BANCO MUNDIAL, 2002, p. 169 - tradução nossa)

As recomendações supramencionadas induzem a várias análises. A primeira é a transposição da experiência de outros países na utilização da $\mathrm{EaD}$ para países do capitalismo periférico como o Brasil, sem considerar que cada país tem suas especificidades, principalmente em se tratando de um país continental e com expressivo déficit de qualidade educacional como o Brasil. Essa recomendação coloca em evidência as relações de consumo de tecnologia que o Brasil efetuaria ao implementar um amplo sistema de EaD.

A segunda questão refere-se à ênfase que o Banco Mundial atribui à criação de instituições que foquem somente no ensino e, consequentemente, não promovam a pesquisa. O Banco Mundial defende uma espécie de reserva de realização da pesquisa aos países desenvolvidos, tentando colocar determinados países na eterna condição de consumidores de conhecimentos.

A terceira questão relevante diz respeito à redução dos gastos do Estado com educação superior e a acomodação da demanda de EaD nos orçamentos já existentes nas universidades públicas federais. Não se trata pois, de novos investimentos para desenvolver uma nova modalidade de educação que, por sua própria especificidade, necessitaria de investimentos em formação e em equipamentos; trata-se de redistribuir os recursos existentes, reduzindo cada vez mais o custo aluno na Educação Superior.

A quarta questão está relacionada à recomendação de que o Brasil deveria apoiar o crescimento da educação privada. Isso ocorreu de forma ampla com a criação Fundo de Financiamento Estudantil (Fies) e do Programa Universidade para todos (Prouni) que oferecem bolsas de estudo em instituições privadas a estudantes de baixa renda.

A quinta questão está relacionada à preocupação com os alunos de famílias com renda familiar mais baixa; no caso do Brasil, essa preocupação tem fundamento, visto que, historicamente, o acesso das camadas populares a esse nível educacional sempre foi muito restrito. No entanto, questiona-se essa

$4 \quad$ If the experience of other countries is any guide, the primary strategy for meeting this growth in demand in Brazil will and should be a diversification strategy that relies principally on creations of distance learning programs and the expansion of enrollments at institutions that do not stress research in their mission. But Brazil should also consider the role of the federal universities in meeting some of this demands. 
preocupação pelo incentivo à redução dos gastos com as instituições públicas, com o incentivo ao setor privado e pela indicação da educação a distância para a expansão da educação superior.

Seguindo essa tendência, o Brasil tem investido em educação a distância, visando a atender a todos os níveis e modalidades, principalmente após a aprovação da Lei no 9.394/1996, de Diretrizes e Bases da Educação. A incorporação da educação a distância ao sistema educacional brasileiro passou a ser não mais uma atividade suplementar, mas substitutiva ao modelo presencial. Isso tem contribuído para aumentar, de forma significativa, as matrículas desse nível de ensino.

\section{EDUCAÇÃO A DISTÂNCIA: UMA ESTRATÉGIA PARA A EXPANSÃO DA EDUCAÇÃO SUPERIOR}

A origem do ensino superior no Brasil é recente se comparada com as antigas universidades europeias ou, até mesmo, com as universidades da América Hispânica. Procedendo a um levantamento histórico da constituição da Educação Superior no Brasil, Martins (2002) deixa explícito que, até a Proclamação da República, em 1889, o ensino superior desenvolveu-se muito lentamente, obedecendo ao modelo de formação dos profissionais liberais em faculdades isoladas. Esse fato não mudou muito nos anos subsequentes, visto que não houve mudanças significativas no formato do sistema. Nesse sentido, pode-se afirmar que o sistema foi-se criando extremamente elitista, o que se refletia no atendimento de parcela mínima da população, sobretudo dos estratos mais privilegiados e com instituições, na sua maioria, privadas.

A criação das universidades e a expansão pela via privada que acompanhou o crescimento do ensino superior no Brasil não foram capazes de reduzir o déficit de atendimento. Dessa forma, chega-se, ao final da década de 1990, com um atendimento deficitário. As novas demandas globais e as orientações dos organismos internacionais para a educação superior foram determinantes para que o Brasil adotasse políticas expansionistas com foco na oferta e complementadas com políticas de equidade com o objetivo de corrigir as deficiências históricas apresentadas nesse nível educacional.

Várias iniciativas foram tomadas nos últimos governos para aumentar a cobertura da Educação Superior no País, entre elas, a educação a distância que passou a ser uma estratégia fulcral para contribuir para a transição do sistema de elite para um sistema de massa. Os estudos efetivados por Trow (1974, 2005,) evidenciam que essa massificação ocorre por vários motivos, entre os quais, merece destaque, inicialmente, a existência de uma expressiva demanda populacional a ser 
atendida, demanda essa que vê, na consecução de um curso superior, uma forma de ascensão social. Outro motivo da ocorrência da massificação é quando o Estado se considera incapaz de suprir essa carência de forma universal ou não julga essa uma política viável do ponto de vista econômico. Por fim, pode-se atribuir às demandas internas e externas que exigem maior capacitação da população para atender às exigências do mundo produtivo, mas, ao mesmo tempo, tendem a precarizar a formação dos trabalhadores.

Estudos realizados por CabralNeto e Castro (2014) evidenciam que o Brasil vem experimentando um processo de expansão da Educação superior, utilizandose da estratégia de educação a distância e incrementando a participação do setor privado na oferta de vagas. Vários marcos normativos deram suporte às políticas para a Educação Superior, entre eles, destaca-se: a Lei no 9.394/96, de Diretrizes e Bases (LDB), que possibilitou a diversificação da oferta e aprovou a utilização da educação a distância, e o Plano Nacional de Educação (2001-2010) que propunha, nas suas metas para a Educação Superior, o provimento da cobertura em, pelo menos, 30\% de jovens na idade de 18 a 24 anos. Essas orientações possibilitaram a implantação de programas governamentais de indução da expansão, favoreceram a organização do sistema de Educação Superior, embora tenham contribuído, de forma muito débil, para o fortalecimento da educação como bem público. Essas medidas beneficiaram o desenvolvimento do setor privado mercantil, que, usufruindo da flexibilização das normas e do uso dos recursos públicos, foi-se ampliando de forma acentuada, de modo que se tornou hegemônico no processo de ampliação da Educação Superior.

As políticas adotadas para a Educação Superior estimularam o uso da Educação a Distância em todos os níveis e modalidades. Em 2007, registra-se um passo significativo nesse sentido com a criação da Universidade Aberta do Brasil (UAB). Os índices indicam que a expansão ocorrida no País permitiu que o sistema evoluísse de um sistema elitista para um sistema de massa.

Diversos indicadores atestam a expansão do ensino superior pela modalidade a distância tanto no setor público quanto no privado. Para efeito deste artigo, consideram-se o número de vagas novas ofertadas, candidatos inscritos e ingressos no setor público pela modalidade a distância (quadro 1) e o número de matrículas nas modalidades no ensino superior a distância nas instituições públicas e privadas (quadro 2). 


\section{Quadro 1 - Evolução do número de vagas, candidatos e ingressos ao Ensino Superior Público na modalidade a distância no período de 2010 a 2016}

\begin{tabular}{|c|c|c|c|c|c|c|}
\hline Ano & $\begin{array}{c}\text { Vagas novas } \\
\text { Oferecidas }\end{array}$ & $\begin{array}{c}\text { Candidatos } \\
\text { Inscritos }\end{array}$ & $\begin{array}{c}\text { Relação } \\
\text { candidato } \\
\text { vaga }\end{array}$ & Ingressos & $\begin{array}{c}\text { Vagas } \\
\text { ociosas } \\
\%\end{array}$ & $\begin{array}{c}\text { Vagas } \\
\text { Preenchidas } \\
\%\end{array}$ \\
\hline $\mathbf{2 0 1 0}$ & 1.634 .118 & 690.921 & 2,3 & 332.028 & 79,69 & 20,31 \\
\hline $\mathbf{2 0 1 1}$ & 1.224 .760 & 797.176 & 1,53 & 406.514 & 69,88 & 30,12 \\
\hline $\mathbf{2 0 1 2}$ & 1.329 .407 & 1.029 .981 & 1,2 & 508.268 & 73,85 & 26,15 \\
\hline $\mathbf{2 0 1 3}$ & 1.638 .427 & 1.429 .360 & 1,14 & 474.120 & 65,45 & 34,55 \\
\hline $\mathbf{2 0 1 4}$ & 2.800 .358 & 2.112 .930 & 1,32 & 691.731 & 56,22 & 43,78 \\
\hline $\mathbf{2 0 1 5}$ & 2.387 .865 & 1.556 .116 & 1,53 & 639.519 & 62,67 & 37,33 \\
\hline $\mathbf{2 0 1 6}$ & 3.936 .573 & 1.944 .081 & 2,02 & 781.708 & 49,65 & 50,35 \\
\hline $\mathbf{\Delta} \%$ & $141 \%$ & $181 \%$ & & $135 \%$ & & \\
\hline
\end{tabular}

Fonte: Adaptado do Brasil/Mec/Inep (Censo da Educação Superior, 2010, 2011, 2012, 2013, 2014, 2015 e 2016)

O uso da modalidade a distância no ensino superior brasileiro é bastante recente. Após a aprovação da Lei nº 9.394/96 - LDB (BRASIL, 2006), iniciativas de regulação foram efetuadas, entre elas, o Decreto no 2.494 e a Portaria $n^{\circ} 301$, ambos de 1998; o setor, porém, só começou a apresentar sinais de crescimento significativo a partir de 2003. A expansão da modalidade da EaD em cursos de graduação ocorre, principalmente, por meio de uma política de indução do governo federal, com a criação da Universidade Aberta do Brasil, em 2006, considerada uma importante estratégia governamental de expansão da Educação superior pela modalidade $\mathrm{EaD}$ e por uma política de financiamento para a iniciativa privada como o ProUni. Segundo Segenreich (2013, p. 33), "do total de bolsas concedidas pelo Ministério da Educação (MEC) para o ProUNi, em 2013, para cursos de graduação, $23 \%$ se destinaram a curso a distância, totalizando 37.783 vagas, financiadas pelo governo federal no sistema privado".

Essas iniciativas aliadas à falta de regulação do MEC para o credenciamento de instituições, visando à oferta dos cursos em $\mathrm{EaD}$, permitiram o crescimento, no período de 2010 a 2016, de 141\% de vagas novas ofertadas. Em 2010, foi ofertado um total de 1.634.118, oscilando, nos anos subsequentes, ora com redução de vagas, ora com aumento do número de vagas, chegando, em 2016, a uma oferta de 3.936.573.

$\mathrm{O}$ número de candidatos inscritos na modalidade de $\mathrm{EaD}$, apesar de haver crescido, em 181\%, não ocorreu na mesma proporção da oferta, tendo em vista que o número de inscritos em nenhum ano superou o número de vagas. No ano de 2010, o número de vagas era em torno de duas vagas para cada 
candidato (2,3). Essa relação chegou, em 2013, a 1,14 candidato vaga, havendo uma evolução insignificante e, em 2016, essa relação alcançou 2,02 candidato vaga. Esses números sinalizam que, apesar de existir uma demanda pelo ensino superior, a modalidade a distância não se apresenta, ainda, como uma alternativa viável para muitos estudantes, tendo em vista fatores como, a falta de autonomia dos estudantes para realizarem seus estudos sem a presença física do professor e a maioria das vagas ofertadas se encontrarem no setor privado.

O crescimento dos ingressantes no ensino superior é de 135\% o que pode ser considerado um número relativamente alto. Porém, uma análise mais detalhada mostra grande ociosidade do sistema. No ano de 2010, foram preenchidas apenas $20,31 \%$ das vagas, enquanto a ociosidade do sistema chegou a $79,69 \%$. No ano de 2011 , foram preenchidas $30,12 \%$ das vagas, revelando que houve uma maior procura por essa modalidade. Mesmo assim, a ociosidade do sistema foi de $69,88 \%$. Em todos os anos, as vagas preenchidas nunca superaram os $50 \%$ da oferta, com exceção do ano de 2016, quando foram preenchidas $50,33 \%$ das vagas.

Alguns fatores podem ser atribuídos a essa ociosidade; entre eles, a falta de interesse dos estudantes; a resistência em fazer um curso de EaD; a metodologia utilizada e a infraestrutura de funcionamento dos cursos. A ociosidade do sistema não deixa de se constituir em um paradoxo, no sentido de que existe uma demanda reprimida por ensino superior, ocasionando uma baixa cobertura no país.

No que se refere à evolução das matrículas no ensino superior na modalidade de $\mathrm{EaD}$, os dados no quadro 2 revelam um crescimento expressivo.

\section{Quadro 2 - Evolução do número de matriculados no ensino superior a distância nas instituições públicas e privadas no período de 2010 a 2016 no Brasil}

\begin{tabular}{|c|c|c|c|c|c|}
\hline Ano & $\begin{array}{c}\text { Total Geral no } \\
\text { Brasil (EAD) }\end{array}$ & $\begin{array}{c}\text { Instituicões } \\
\text { Públicas } \\
\text { (EAD) }\end{array}$ & $\begin{array}{c}\text { Instituições } \\
\text { Privadas } \\
\text { (EAD) }\end{array}$ & $\begin{array}{c}\text { Participação / } \\
\text { Público } \\
\%\end{array}$ & $\begin{array}{c}\text { Participação/ } \\
\text { privada } \\
\%\end{array}$ \\
\hline $\mathbf{2 0 1 0}$ & 930.179 & 181.602 & 748.577 & 19,51 & 80,48 \\
\hline $\mathbf{2 0 1 1}$ & 992.927 & 177.924 & 815.003 & 17,91 & 82,1 \\
\hline $\mathbf{2 0 1 2}$ & 1.113 .850 & 181.624 & 932.226 & 16,30 & 83,70 \\
\hline $\mathbf{2 0 1 3}$ & 1.153 .572 & 154.553 & 999.019 & 13,39 & 86,61 \\
\hline $\mathbf{2 0 1 4}$ & 1.341 .842 & 139.373 & 1.202 .469 & 10,30 & 89,61 \\
\hline $\mathbf{2 0 1 5}$ & 1.393 .752 & 128.393 & 1.265 .359 & 9,22 & 90,78 \\
\hline $\mathbf{2 0 1 6}$ & 1.494 .418 & 122.601 & 1.371 .817 & 8,21 & 91,79 \\
\hline $\mathbf{\Delta} \%$ & $\mathbf{6 1 \%}$ & $\mathbf{- 3 2} \%$ & $83 \%$ & & \\
\hline
\end{tabular}

Fonte: BRASIL/MEC/INEP, 2017 - Adaptação nossa. 
A modalidade de EaD tem contribuído com o crescimento da Educação superior, tanto no setor público quanto no setor privado com forte predominância desse último. Seguindo as orientações dos organismos internacionais, associado à grande demanda interna e à forte pressão do setor privado para implementar políticas que estimulassem o uso da $\mathrm{EaD}$, o Ministério da Educação, no período de 2000 a 2001, inicia um processo de credenciamento de instituições públicas para ofertar cursos superiores pela modalidade de educação a distância, sendo a maioria voltada para integrar consórcios.

Dados analisados por Segenreich (2013) mostram que a EaD em instituições privadas só começou a aparecer no ano de 2002, com apenas nove instituições credenciadas para a sua oferta. No entanto, a falta de regulamentação específica e a facilidade encontrada pelas instituições para criar cursos nessa modalidade viabilizaram a expansão e, no ano de 2005, esse setor já despontava com 38 instituições credenciadas, enquanto o setor público aparecia com apenas 23 instituições.

A expansão se consolida nos anos subsequentes, como pode ser verificado no quadro 2. O crescimento total das matrículas na educação a distância no Brasil entre os anos de 2010 a 2016 foi de 61\%, ano a ano, registrando-se um crescimento sempre ascendente. Esses números têm contribuído significativamente para a transição de um sistema de elite para um sistema de massas. Essa expansão, porém, ocorre não pela democratização do ensino mas por sua privatização. Esse fenômeno é observado quando se verifica a participação do setor privado nas matriculas. No setor público há, no cômputo geral, uma redução de $-32 \%$ das matrículas no período de seis anos e um crescimento de $83 \%$ do setor privado, sinalizando que esse setor vem aumentando a sua participação, de forma significativa, na oferta de educação a distância.

O período de 2010 a 2016 evidencia a consolidação da modalidade da educação a distância no ensino superior privado com um percentual de 91,79\% de todas as matrículas da modalidade a distância. Tomando-se como referência o ano de 2010, a série mostra a evolução da participação do número de matrículas do setor privado. Nesse ano, o número de matrículas é de 930.179 alunos; dessas matriculas, apenas 19,52\% estão nas instituições públicas, enquanto 80,48\% estão nas instituições privadas. Há uma pequena variação no número de matrículas no setor público nos anos de 2011 e 2012, mas sem ultrapassar o número de matrículas no setor privado. No ano de 2013, a redução do setor público nas matrículas é muito acentuada (13,39\%). No ano de 2016, a participação do setor público é de apenas $8,21 \%$ contra $91,79 \%$ das matriculas privadas. Caso essa tendência continue, é provável que a educação a distância passe a ser responsabilidade da iniciativa privada, com sérias repercussões na qualidade de ensino. 
Vários motivos contribuíram para a expansão da $\mathrm{EaD}$ em instituições privadas, entre elas, o longo período em que o sistema educacional de $\mathrm{EaD}$ ficou sem a devida regulamentação no pós-LDB. A esse respeito, Segenreich e Castro (2012) afirmam que é recente no Brasil a criação de "[...] normas e regras em matéria de Educação Superior, principalmente no que se refere à modalidade de ensino a distância e sua utilização na Educação Superior" (p. 91). Ademais, afirmam as autoras que a excessiva flexibilização possibilitada pela LDB no 9.394/96 facilitou o domínio da iniciativa privada e provocou uma expansão desordenada dessa modalidade de educação, em padrões de qualidade frágeis e fora de controle e da avaliação pelos órgãos oficiais competentes.

Outro fator que contribuiu para a mercantilização das matrículas está relacionado à disputa pelo financiamento público por parte do setor privado, que tem vislumbrado grandes possibilidades de auferir lucro e de encontrar no Estado a solução para as constantes crises de acumulação que o referido setor vem enfrentando.

Considera-se que o espaço de ampliação da privatização foi conseguido no vácuo deixado pelas universidades públicas que, a princípio, não se envolviam institucionalmente com a $\mathrm{EaD}$, inclusive por que havia resistência por parte da comunidade acadêmica. Analisando as sucessivas regulamentações e as práticas de inserção dessa modalidade de educação nas universidades consolidadas, Segenreich (2013), conclui que a $\mathrm{EaD}$ foi institucionalmente marginalizada, no início da sua implantação, pelo próprio MEC que criou um espaço paralelo, cada vez mais, difícil de ser avaliado em termos de sua intencionalidades e efeitos, decorrentes dessa prática.

Assim, a expansão da Educação Superior no Brasil pós LDB nº 9.394/96 ocorre pela imbricação ou superposição do setor privado em detrimento do setor público nesse processo híbrido, mas altamente tendencioso ou direcionado para a utilização de financiamento do Estado como meio para a satisfação dos interesses do capital. Nesse sentido, mesmo que tenha sido observado um amplo crescimento da Educação Superior pública, concomitantemente se constata um aumento das instituições privadas bem superior ao da rede pública, principalmente com investimento público no setor privado, desobrigando o Estado, cada vez mais, de suas funções sociais e da sua opção pela educação como bem público. 


\section{CONSIDERAÇÕES FINAIS}

As políticas para a Educação Superior nas últimas décadas têm procurado adequar-se, cada vez mais, às exigências globais. Isso tem reforçado a busca por alcançar padrões cada vez mais amplos de cobertura desse nível de ensino, o que tem possibilitado que os sistemas de Educação Superior, se transformem de sistemas de elite em sistemas de massa. Tradicionalmente, o ensino superior ofertado no Brasil era preferencialmente na modalidade presencial, com formas de ingresso extremamente seletivas, não permitindo a incorporação de grande parcela da população a esse nível de ensino, caracterizando, assim, um sistema de elite.

Visando a ampliar a cobertura e a atingir padrões internacionais de atendimento a esse nível de ensino, o país vem buscando estratégias diversificadas, influenciadas por atores políticos e econômicos de relevância internacional, que têm orientado as políticas de expansão pela modalidade de EaD.

Os estudos desenvolvidos sobre o fenômeno da expansão da Educação Superior a distância identificam que essa modalidade vem aumentando, cada vez mais, sua participação no número de matrículas efetivadas do país. Esse fato tem contribuído para aumentar a taxa líquida de cobertura, possibilitando que o sistema educacional brasileiro assuma características de um sistema de massa, na perspectiva defendida por Trow $(1974,2005)$. Essa é uma tendência que vem crescendo nos últimos anos e conta com as orientações dos organismos internacionais. Os dados estatísticos evidenciam que a tendência à massificação da Educação Superior está em pleno curso e poderia estar mais consolidada se o número total das vagas ofertadas fosse preenchido.

O processo de expansão da Educação Superior na modalidade a distância ocorre nos setores público e privado. Há, porém, uma clara tendência à privatização desse nível de ensino, com forte indução de políticas públicas, o que vem sendo observado com a implementação de inúmeros programas governamentais. A incorporação do grande contingente de alunos ao sistema de Educação Superior modificou a estrutura desse nível de educação no Brasil, visto que a transição de um sistema de elite para um sistema de massa não ocorre sem as tensões inerentes à existência de formas diversificadas de educação, com princípios e funções fundamentalmente diferentes.

Dessa forma, modifica-se o padrão usual de oferta da Educação Superior, anteriormente realizado predominantemente em universidades de natureza pública, voltadas para a formação de elites, para a produção do conhecimento e para o desenvolvimento de uma cultura geral. O que se observa é a predominância crescente da oferta de ensino superior em instituições privadas associada a um 
aumento significativo da educação a distância, em especial nas faculdades, em um movimento que tende a se acentuar em função das recentes políticas para o ensino superior.

\section{REFERÊNCIAS}

BANCO MUNDIAL. Higher Education in Brazil: Challenges and Options. Washington - D.C. EUA, 2002.

BANCO MUNDIAL. Higher Education in Developing Countries: Peril and Promisses. Washington - D.C. EUA, 2000.

BANCO MUNDIAL. Prioridades y estratégias para la educación: examen del Banco Mundial. WASHINGTON - D.C. EUA, 1996.

BERNHEIM, Carlos Tünnermann; CHAUÍ, Marilena de Souza. Desafios da universidade na sociedade do conhecimento: cinco anos depois da Conferência Mundial sobre Educação Superior. Brasilia: UNESCO, 2008. Disponível em: <http://unesdoc.unesco.org/images/0013/001344/134422por. pdf.>. Acesso em: 14 fev. 2015.

BRASIL. Ministério da Educação. Instituto Nacional de Estudos e Pesquisas Educacionais Anísio Teixeira. Censo da Educação superior 2016. Notas Estatísticas. Disponível em http://download.inep.gov.br/educacao_superior/ censo_superior/documentos/2016/notas_sobre_o_censo_da_educacao_ superior_2016.pdf. Acesso em: 20 de fev. 2018a.

Ministério da Educação. Instituto Nacional de Estudos e Pesquisas Educacionais AnísioTeixeira. Censo da Educação superior 2016. Notas Estatísticas. Disponível em http://download.inep.gov.br/educacao_superior/ censo_superior/documentos/2016/notas_sobre_o_censo_da_educacao_ superior_2016.pdf. Acesso em: 20 de fev. 2018b.

Ministério da Educação. Instituto Nacional de Estudos e Pesquisas Educacionais Anísio Teixeira. Censo da Educação superior (2010, 2011, 2012, 2013, 2014, 2015, 2016). Resumo técnico. Brasilia: Disponível em: http:// portal.inep.gov.br/censo-da-educacao-superior. Acesso em 12 dez.2017. 
. Senado Federal. Lei de Diretrizes e Bases da Educação Nacional, $\mathbf{n}^{\circ}$. 9.394 de 20 de dezembro de 1996. Brasília: Subsecretaria de Edições Técnicas, 2006.

- Ministério da Educação. Instituto Nacional de Estudos e Pesquisas Educacionais Anísio Teixeira (INEP). Dicionário de Indicadores Educacionais: fórmulas de cálculo. Brasília, 2004.

. Senado Federal. Lei n ${ }^{\circ}$ 010172, de 9 de janeiro de 2001. Aprova o Plano Nacional de Educação e dá outras providências.www2.camara.leg.br/legin/fed/ lei/2001/lei-10172-9-janeiro-2001-359024-publicacaooriginal-1-pl.html. Acesso em Dez de 2017.

CABRAL NETO, Antônio; CASTRO, Alda Maria Duarte Araújo. Educação Superior no Brasil: os contraditórios caminhos da expansão pós-LDB. In: BRZEZINSKI, Iria (org.). LDB/1996 Contemporânea: Contradições, tensões, compromissos. São Paulo. Cortez Editora. 2014.

CABRITO, Belmiro. Economia da Educação. Lisboa: Texto Editora, 2002. (Coleção Educação Hoje).

CASTELLS, Manuel. A era da informação: economia, sociedade e cultura. 5. ed. São Paulo: Paz e Terra. v. 1. 1999.

MARTINS, Antonio Carlos Pereira. Ensino superior no Brasil: da descoberta aos dias atuais. Acta Cir. Bras. vol.17 suppl.3 São Paulo 2002. Disponível em: http:/ / dx.doi.org/10.1590/S0102-86502002000900001. Acesso em 12 dez.2017.

OLIVEIRA, Romualdo Portela de. Reformas educativas no Brasil na década de 90. Belo Horizonte: Autêntica, 2000.

SCHULTZ, Theodore W. Investment in Human Capital. The American Economic Review. v. 51, no 1, p. 1-17, mar/1961.

SEGENREICH, Stela C. D.. Relação estado e sociedade na oferta e regulação da graduação a distância no Brasil: da periferia ao centro das políticas públicas. In: SEGENREICH, Stela C. D.; BUSTAMANTE, Sílvia Branco Vidal. Políticas e Práticas da Educação a Distância (EAD) no Brasil: entrelaçando pesquisas. Rio de Janeiro: Letra Capital, 2013. 
SEGENREICH, Stela C. D.; CASTRO, Alda M. D. A. A inserção da educação a distância no ensino superior do Brasil: diretrizes e marcos regulatórios. Revista Educação em Questão, Natal, v. 42, n. 28, jan./abr. 2012.

SIGUISSARDI, Valdemar. Educação superior no Brasil. Democratização ou massificação mercantil? Educ. Soc., Campinas, v. 36, nº. 133, p. 867-889, out.dez., 2015.

TROW, Martin. A Reflections on the Transition from Elite to Mass to Universal Access: Forms and Phases of Higher Education in Modern Societies since WWII. 2005. Disponível em https://escholarship.org/uc/item/96p3s213. 2005. Acesso em 06 jan. 2018.

Problems in the Transition from Elite to Mass Higher Education. In: Policies for Higher Education, from the General Report on the Conference on Future Structures of Post-Secondary Education, 55-101. Paris: 1974. OECD. DISPONÍVEL EM: https://files.eric.ed.gov/fulltext/ED091983.pdf. Acesso em: 20 dez. 2017.

UNESCO. Trends in Global Higher Education: tracking an Academic Revolution. A Report prepared for the Unesco 2009 World Conference Higher Education. Unesco, 2009.

Conferencia Mundial sobre la Educación Superior 2009: La nueva dinâmica de la educación superior y la investigación para el cambio social y el desarrollo. París, 2009. Disponível em: <http://www.unesco.org/education/ WCHE2009/comunicado_es.pdf>. Acesso em: 20 abr. 2015.

Conferencia Mundial sobre la Educación Superior 1998: La educación superior em el siglo XXI - visión y acción. París, 1998. http://www. unesco.org/education/educprog/wche/declaration_spa.htm. Acesso em: 20 de abr.2015.

\footnotetext{
ALDA MARIA DUARTE ARAÚJO CASTRO é Doutora em Políticas Educacionais pela Universidade Federal do Rio Grande do Norte. Professora Associada do Centro de Educação e Professora do Programa de Pós-Graduação em Educação da Universidade Federal do Rio Grande do Norte e Coordenadora do Laboratório de Políticas Educacionais da UFRN. E-mail: aldacastro@hotmail.com
} 
NATANIEL DA VERA-CRUZ GONÇALVES ARAÚJO é Doutor em Educação pela Universidade Federal do Rio Grande do Norte, realizou Doutoramento Sanduíche na Universidade de Lisboa (Portugal). Professor da Universidade Federal do Tocantins (UFT). Tem experiência na docência superior com ênfase nas áreas de Formação de Professores, Políticas Educacionais, Sociologia da Educação e Tecnologia Educacional. E-mail: nataniel@mail.uft.edu.br

Recebido em fevereiro de 2018 Aprovado em abril de 2018 